Emotion in everyday risk perception

\title{
Emotion and reason in everyday risk perception
}

Robin M. Hogarth, Mariona Portell, Anna Cuxart, \& Gueorgui I. Kolev

July 23, 2009 


\begin{abstract}
Although research has documented the importance of emotion in risk perception, little is known about its prevalence in everyday life. Using the Experience Sampling Method, 94 part-time students were prompted at random - via cellular telephones - to report on mood state and three emotions and to assess risk on thirty occasions during their working hours. The emotions valence, arousal, and dominance - were measured using self-assessment manikins (Bradley \& Lang, 1994). Hierarchical linear models (HLM) revealed that mood state and emotions explained significant variance in risk perception. In addition, valence and arousal accounted for variance over and above "reason" (measured by severity and possibility of risks). Six risks were reassessed in a post-experimental session and found to be lower than their real-time counterparts. The study demonstrates the feasibility and value of collecting representative samples of data with simple technology. Evidence for the statistical consistency of the HLM estimates is provided in an Appendix.
\end{abstract}

Keywords: representative design; experience sampling method; risk perception; emotional reactions; self-assessment manikins (SAM); retrospective judgment; multilevel analysis. 


\section{INTRODUCTION}

Perceptions of risk are important in guiding human actions. What, however, drives these perceptions? From a rational viewpoint, risk perception should reflect what is at stake and the probability of loss. In insurance, for example, premiums reflect potential losses and their probabilities of occurrence.

However, much research has documented that emotions are also important in risk perception (Slovic, 2000; Loewenstein et al., 2001; Slovic et al., 2004; Slovic \& Peters, 2006. For example, in a field experiment conducted after September 11, 2001, Lerner et al. (2003) showed how fear and anger affected perceived risks of terrorism. Other effects have been demonstrated in psychological laboratories where researchers have deliberately manipulated mood states to observe effects on perceived risk. Rottenstreich and Hsee (2001), for example, showed that when outcomes of uncertain actions involve strong affect (positive or negative), reactions are relatively insensitive to large variations in the probability of the outcomes occurring (see also Hsee \& Kunreuther, 2000; Slovic et al., 2002; Sunstein, 2003). Interestingly, Andrade and Ariely (2009) find that decisions based on fleeting incidental emotions can also affect future decisions even after the initial emotion has subsided.

That emotions and rational thinking should both affect perceptions of risk is supported by current theorizing on dual processes of cognition that suggest that judgments can reflect two systems of thought (Chaiken \& Trope, 1999; Kahneman \& Frederick, 2002) sometimes referred to as experiential and analytic, respectively (Epstein, 1994). The major distinction between the systems is that whereas the analytic system requires conscious effort and works in an explicit step-by-step manner, the experiential is largely covert and relies heavily on rapidly processed 
feelings or emotions that a person may not be able to specify. That is, the analytic system can be thought of as involving reason with the experiential depending heavily on emotions. This is not to say, however, that the experiential system is only used when emotions are important (e.g., post September 11, 2001). On the contrary, the claim has been made that even modest levels of emotions - in the form of moods or affect - form the background to much of everyday thinking. Indeed, Slovic et al. (2002), have coined what they call "the affect heuristic" to describe the use of affect in everyday decision making and make the point that - since emotions have developed through evolutionary processes - they are often functional and "rational" in their use.

The fact that emotions can affect perceptions of risk has been well demonstrated. And yet, despite these demonstrations, little is known about how the findings relate to the ordinary activities of everyday life. For example, if you obtained a random sample of a person's risk perceptions, what would be the effect of emotion? Moreover, what are the relative contributions of emotional and rational considerations in representative samples of people's experiences? Finally, do perceptions of daily risks at the time they are confronted differ systematically from, say, retrospective assessments?

To investigate these issues, we conducted a study based on the principles of representative design advocated by Egon Brunswik (Brunswik, 1944; 1956; see also Dhami, Hertwig, \& Hoffrage, 2004; Hogarth, 2005). Specifically, we collected data on individuals' risk perceptions and emotions by having them complete prepared response sheets when triggered by text messages sent to their cellular telephones at random moments during their working days. Participants reported on their mood state, current activity, emotional reactions, and how they perceived the risks entailed. In short, by using cellular telephones (owned by our respondents), we implemented the Experience Sampling Method (ESM) (Hurlburt, 1997; Hektner, Schmidt, \& 
Csikszentmihayli, 2007) and collected random samples of behavior in everyday settings. ${ }^{1}$ As such, we can make meaningful, generalizable statements about the emotion-risk perception link in the populations of situations experienced by our participants.

In summary, we find that perceptions of risks encountered in everyday life are related to deviations in participants' mood states and emotional reactions. Moreover, these affective variables explain variance in risk perception over and above rational considerations (captured by estimates of the possibilities and consequences of losses). We also provide evidence that when risk perception is measured in real time, it differs significantly from retrospective recollections. Finally, these statements are all made using regression analyses that assume consistent estimation of statistical parameters. An Appendix shows that this assumption is reasonable.

\section{STUDY}

\section{Participants}

Ninety-four students (64 women and 30 men) were recruited from the Universitat Autònoma de Barcelona. They ranged in age between 17 and 28 (median 19). A condition of their participation was that they had part-time jobs (defined by at least one third of full working days). They were paid 35 euros (approximately \$50) for their participation that, in addition to responding to the questions detailed below, required attendance at sessions before and after the experiment for instructions and debriefing.

\footnotetext{
${ }^{1}$ Curiously, in discussing the origins of the Experience Sampling Method (ESM), Hektner et al. (2007) make no reference to Brunswik's prior work, see e.g., Brunswik (1944). One reason might be that Brunswik used a human judge to collect data as opposed to instruments such as timers, hand-held PDAs etc.
} 


\section{Procedure}

We sent text messages to participants between 8 am and $10 \mathrm{pm}$ over a two-week period that excluded week-ends, i.e., for 10 consecutive working days. Depending on their working hours, some participants received their messages between 8 am and $3 \mathrm{pm}$ and the others between $3 \mathrm{pm}$ and $10 \mathrm{pm}$ (12 and 82 participants, respectively). ${ }^{2}$ To determine when messages should be sent, we divided time into segments of 15 minutes and chose six segments at random each day (three for each group of participants).

When they received a message, participants were required to note the date and time and to answer a series of questions. ${ }^{3}$ The questions, their scales, and the abbreviations we use, were:

1. How would you evaluate your emotional state right now? Scale from 1(very negative) to 10 (very positive): mood state.

2. What are you doing right now? Open-ended and subsequently referred to as ACT: activity.

3. Is ACT professional or personal in nature? Binary response: type.

4. Emotional response to ACT - see description below.

5. What is the WORST consequence that could result from ACT? Open-ended: worst consequence.

6. How do you rate the severity of the WORST consequence that could result from ACT? Scale from 1 (very low) to 10 (very high): severity.

7. At this moment, what is the chance that the WORST consequence of ACT occurs? Scale from 0 (impossible) to 100 (certain): possibility.

\footnotetext{
${ }^{2}$ The objective was to send participants messages during the part of the day in which they were mainly at work.

${ }^{3}$ All questions were asked in Spanish.
} 
8. At this moment, what risk for your well-being do you associate with ACT? Scale from 0 (very low) to 100 (very high): risk.

Emotional responses (i.e., 4) were measured using self-assessment manikins (SAMs) (Bradley \& Lang, 1994) - see Figure 1. These represent visually three basic dimensions of emotions in reactions to events or situations. They are (a) valence (or pleasure), (b) arousal, and (c) dominance. Participants simply checked the figure - or between adjacent figures - in each line that corresponded most to their feelings (thereby implicitly using 9-point scales ${ }^{4}$ ).

Figure 1 about here

Our use of SAMs was based on theoretical, methodological, and practical considerations. First, the three SAM dimensions have the advantage of covering a range of possible emotional reactions to a situation and are theoretically based. To quote Bradley and Lang (1994):

....differences in affective meaning among stimuli - words, object, events - can be described by three basic dimensions that Wundt (1896) originally labeled lust (pleasure), spannung (tension), and beruhigung (inhibition). Following Wundt's theoretical categories, empirical work has repeatedly confirmed that pleasure, arousal, and dominance are pervasive in organizing human judgments for a wide range of perceptual and symbolic stimuli. (p. 49).

Second, the SAMs have been shown to have good properties when validated against more complete instruments (Bradley \& Long, 1994). And third, the SAMs are quite intuitive and thus easy for respondents to use. Given the lack of prior work linking the SAMs to risk perception, we did not formulate specific hypotheses. However, given that our study focused on negative consequences of risk, one might assume that "positive" emotions would be associated with less risk. Thus our intuitions were that while greater feelings of pleasure and dominance would be

\footnotetext{
${ }^{4}$ In coding, we labeled responses on the extreme left "1" and those on the extreme right "9".
} 
associated with lower perceived risk, more arousal would be associated with increases in perceived risk.

After completing the task, participants were thanked, debriefed, and paid in a session in which they classified some of their open-ended responses into categories we had established previously and also re-assessed the severity, possibility, and risks associated with six activities on which they had reported in the preceding weeks.

\section{Study design}

To control for possible response bias, we created two conditions - "long" and "short." In the long condition, participants answered questions in the order indicated above. In the short condition, risk was assessed before emotional reactions (i.e., number 8 before number 4 ) and there were no questions about the precise risk and its associated severity and possibility (i.e., numbers 5, 6, and 7). Thirty-four females were assigned at random to the first condition, and 30 to the second. All 30 males participated in the first condition.

\section{Data analysis}

The design of our study involved data that can be thought of as being collected at two levels. One of these levels - termed level 1 - is represented by participants' responses to the 30 occasions on which they received text messages (i.e., at the level of events). The other - level 2 - is at that of the participants themselves (i.e., characteristics of the participants that do not change across the 30 events). Thus, for example, it is of interest to know whether, say, mood state at the moment judgments are elicited are associated with assessments of risk (i.e., at level 1) and also whether such judgments reflect differences between the participants in, say, gender (i.e., 
at level 2). As such, our data can be efficiently modeled using the techniques of hierarchical linear models (Bryk \& Raudenbush, 2002; Goldstein, 1995; Longford, 1994).

We motivate our use of hierarchical linear models (HLMs) with an example. Assume we wish to model risk as being related to mood state (at level 1) but that this is moderated by gender (at level 2).

Define the model at level 1 as

$$
Y_{i j}=\beta_{0 j}+\beta_{1 j}\left(X_{i j}-\bar{X}_{. j}\right)+r_{i j}
$$

where

$Y_{i j}$ is the judgment of risk on the $\mathrm{i}^{\text {th }}$ occasion $(\mathrm{i}=1, . ., 30)$ for the $\mathrm{j}^{\text {th }}$ individual $(\mathrm{j}=1, \ldots, 94)$;

$\left(X_{i j}-\bar{X}_{. j}\right)$ is the deviation of the reported mood state $X_{i j}$ on the $\mathrm{i}^{\text {th }}$ occasion for the $\mathrm{j}^{\text {th }}$ individual from his or her average mood state $\bar{X}_{. j}$;

$\beta_{0 j}$ is the individual-specific intercept;

$\beta_{1 j}$ is the individual-specific slope (regression coefficient) of $Y_{i j}$ on $\left(X_{i j}-\bar{X}_{. j}\right)$; and $r_{i j}$ is the error term which we assume normally distributed with constant variance, $r_{i j} \sim \mathrm{N}\left(0, \sigma^{2}\right)$.

Define the model at level 2 as

$$
\beta_{0 j}=\gamma_{00}+\gamma_{01} Z_{j}+u_{0 j}
$$

and

$$
\beta_{1 j}=\gamma_{10}+\gamma_{11} Z_{j}+u_{1 j}
$$

where

$Z_{j}=$ gender of participant $(0$, female, or 1, male $) ;$

$\gamma_{00}$ is the constant part of the intercept $\beta_{0 j}$;

$\gamma_{01}$ is the regression coefficient of $\beta_{0 j}$ on $Z_{j}$; 
$u_{0 j}$ is an error term (the individual effect on judgments of risk);

$\gamma_{10}$ is the constant part of the slope $\beta_{1 j}$;

$\gamma_{11}$ is the effect of gender on the slope $\beta_{1 j}$ (i.e., the interaction of gender and mood state on judgments of risk);

$u_{l j}$ is an individual error term, that is, the random interaction effect of individual $j$ and mood state on judgments of risk.

Thus, to interpret the above, $\gamma_{00}$ is the average risk score across all women, while $\gamma_{00}+\gamma_{01}$ is the average risk score across all men; $\gamma_{10}$ is the average effect across women of mood state on judgments of risk, while $\gamma_{10}+\gamma_{11}$ represents the average effect across men of mood state on judgments of risk. We assume that $u_{0 j}$ and $u_{1 j}$ are random variables with zero means, variances $\tau_{00}$ and $\tau_{11}$, respectively, and covariance $\tau_{01}$; they represent the variability in $\beta_{0 j}$ and $\beta_{1 j}$ that remains after controlling for $Z_{j}$. In addition, the level 2 error vector $\left(u_{0 j}, u_{1 j}\right)$ is assumed to have a bivariate normal distribution and to be independent of the level 1 error terms $r_{i j}$.

Substituting equations (2) and (3) into (1), we obtain

$$
Y_{i j}=\gamma_{00}+\gamma_{01} Z_{j}+u_{0 j}+\left(\gamma_{10}+\gamma_{11} Z_{j}+u_{1 j}\right)\left(X_{i j}-\bar{X}_{. j}\right)+r_{i j}
$$

which can be re-arranged as

$$
Y_{i j}=\gamma_{00}+\gamma_{01} Z_{j}+\gamma_{10}\left(X_{i j}-\bar{X}_{. j}\right)+\gamma_{11} Z_{j}\left(X_{i j}-\bar{X}_{. j}\right)+u_{0 j}+u_{1 j}\left(X_{i j}-\bar{X}_{. j}\right)+r_{i j}
$$

Note that, in the latter expression, one can distinguish the fixed part, $\gamma_{00}+\gamma_{01} Z_{j}+\gamma_{10}\left(X_{i j}-\bar{X}_{. j}\right)+\gamma_{11} Z_{j}\left(X_{i j}-\bar{X}_{. j}\right) \quad$ (with main effect for $Z$, main effect for $X$ and 
their interaction), from the random part, $u_{0 j}+u_{1 j}\left(X_{i j}-\bar{X}_{. j}\right)+r_{i j}$ (with individual random effect, random interaction between the $j^{\text {th }}$ individual and $X$, and occasion-specific error term).

We have only illustrated the model by considering one independent variable at level 1 (mood state) and one independent variable at level 2 (gender). However, it is straightforward to construct more complete models by considering vectors of independent variables at both levels.

Finally, we note that our research design involves correlational data and does not permit causal inferences. However, to obtain statistically consistent estimates, the hypothesis of regression is that the dependent variable (here risk perception) is impacted by the independent variables (here emotional variables, inter alia) as opposed to vice-versa. We therefore provide a test of the consistency hypothesis (see below and Appendix).

\section{RESULTS}

From the 2,820 (=94 × $10 \times 3)$ messages sent, 2,809 were received (99.6\%). On average, participants responded between zero and ten minutes after reception (overall mean of one minute). The distribution of types of activities and risks was similar to a previous study (Hogarth, Portell, \& Cuxart, 2007) and is not presented here. 


\section{Emotion: Mood and emotional reactions}

Table 1 reports HLM results of regressing perceived risk on mood and emotional reactions as well as gender. ${ }^{5}$ We first note that we rescaled variables that were measured on a $0-100$ scale to a 0-10 scale (risk and possibility) in order to facilitate comparisons. We present four models.

\section{Table 1 about here}

Model 1 estimates the mean risk level of risk perception; this is 2.56 on a $0-10$ scale.

In Model 2, we introduce mood state and gender. For mood state, we coded participants' mean mood assessments across the 30 occasions to serve as a proxy for individual dispositions, that is, a level 2 variable. At level 1, we use the deviations from these means. These mood deviations are significant. In short, being in a better mood is associated with lower perceived risk, a result that replicates earlier work (Hogarth et al., 2007). However, at level 2 there is no significant dispositional effect for mood (i.e., mean mood state). In other words, there is no relation between the mean level of participants' mood assessments and their perceptions of risk.

Gender appears to play a role. On average, males give higher risk assessments than females. This last result is contrary to most findings (Byrnes, Miller, \& Schafer, 1999) including our own (Hogarth et al., 2007) and we conclude it is a peculiarity of this sample. ${ }^{6}$

In Model 3, we substitute the SAM variables for mood state deviations at level 1. Given the way these variables are scaled (see Figure 1), the coefficients imply that less risk is

\footnotetext{
${ }^{5}$ All results of HLM in this paper are based on maximum likelihood estimation. Intercepts are estimated as random whereas slope coefficients are estimated as fixed. We have also conducted additional analyses where both intercept and slope coefficients are estimated as random. However, since this change of specification does not change our main results, they are not provided here. (More information on this point is available from the authors.)

${ }^{6} \mathrm{We}$ conducted several analyses to determine possible causes of this gender difference. In short, we found no significant difference in the types of losses faced by men and women. Moreover, we found a significant gender difference in risk assessment for only one of five job classifications. Female health and educational workers perceived significantly less risk, on average, than their male counterparts. This appears to drive the result that males give higher risk assessments than females. As it is only one job classification, we do not consider it important. (More information on this point is available from the authors.)
} 
associated with greater valence (pleasure), more risk is associated with greater arousal, and less risk is associated with more dominance. These are in accordance with out intuitions detailed above.

Model 4 tests the joint effects of both the mood state deviations and the SAM variables. All explain significant variance in perceived risk at level 1. However, there is some redundancy between the two as demonstrated by the fact that the coefficient for mood state deviations is diminished in the presence of the SAM variables (from -0.28 to -0.12).

Finally, whereas HLM regressions do not allow simple interpretations in terms of conventional $\mathrm{R}^{2}$, we show the effects of the different classes of variables in terms of reduction in estimated prediction error relative to Model 1. By this measure, at level 1 Model 2 (mood state deviations) accounts for a reduction in variance of $8.2 \%$, Model 3 (the SAM variables) accounts for $13.3 \%$, and Model 4 (mood state deviations and the SAM variables) $13.7 \% .^{7}$

These results are important. They extend findings of the risk-emotion relation from experimental and field studies to random samples of real-time, everyday judgments. Mood can be thought of as operating at two levels - mean mood state (a dispositional measure of "how happy" people are, on average) and mood state deviations (or specific momentary effects). We found no effect for mean mood state (at level 2) but respondents perceived less risk when in a more positive mood state (at level 1). However, mood deviations explain less variance than emotional reactions. In our data, "happier" valence (left of Figure 1a) is associated with less risk, as are less arousal (right of Figure 1b) and greater dominance (right of Figure 1c).

Although not provided here, we conducted further analyses to test for possible effects of additional moderators as well as robustness. Of particular interest is the fact that questionnaire

\footnotetext{
${ }^{7}$ In addition, Tables 1 and 2 include estimates of the level 2 proportion of variance. These measures are calculated as the proportional reduction of error for predicting an individual mean (mean perceived risk). For specific details about how these concepts were elaborated, see Snijders and Bosker (1999, ch.7).
} 
type ("short" versus "long" - in which the order of questions about risk and emotional reactions were reversed) had no significant effect. The conclusions stated above were not changed by these additional analyses. ${ }^{8}$

\section{Reason and emotion}

From a rational perspective, perceived risk should reflect assessed severity and possibility of risks (i.e., reason). If it does, what is the role of emotion (mood state and the SAM variables)? Using data only from the (long) condition where participants provided assessments of severity and possibility, we employ HLM to answer this question.

\section{Table 2 about here}

Table 2 reports results of five models that progressively introduce effects of reason and emotion. Model 1 simply estimates the overall mean of risk judgments as 2.88 . Model 2 shows the separate effects of severity and possibility at level 1 . Note this involves a reduction in variance at level 1 of $24.4 \%$ compared to Model 1. Model 3 adds the interaction between severity and possibility and the reduction in variance between Models 1 and 3 is now 26.2\%. Interestingly, Model 3 highlights (as one would expect) the importance of the severity $\mathrm{x}$ possibility interaction. However, this is augmented by a main effect for severity (but not possibility) that suggests more perceived risk for more severe events independent of their probability of occurrence (Model 3).

Mood is introduced in Model 4. This shows that mood state deviations, by themselves, add significant variance over and above reason even though the increase in reduction of variance

\footnotetext{
${ }^{8}$ All of these additional analyses can be obtained from the authors.
} 
is small - from $26.2 \%$ to $29.4 \%$. With the introduction of the SAM variables in Model 5, the reduction in variance increases (marginally) to $29.5 \%$.

Table 2 describes how reason and emotion jointly account for significant variance in risk perception. We make two points. First, the signs of the coefficients for mood state deviations and the SAM variables are the same as in the larger sample presented in Table 1. However, in the presence of severity and possibility, the SAM variable of dominance is no longer significant and the effect of mood state deviations is weaker. Second, although the reduction of variance at level 1 relative to Model 1 is greater for reason than for emotion, the latter is still significant and adds to explaining risk perception. ${ }^{9}$ In summary, we can say that both reason and emotion are jointly implicated in everyday risk perception thereby providing support to theorizing on dual processes of cognition discussed in the introduction.

\section{Real-time versus retrospective judgments}

After the study, participants re-assessed risks associated with six occasions (sampled from the middle of the first and second weeks of data collection) and also stated whether these had materialized.

Previous findings indicate that events experienced in real-time are judged as riskier than the same events considered retrospectively (Hogarth et al., 2007). Whereas negative emotions at the time events are experienced could explain these results, other factors such as effects of time on memory (more recent events being recalled more accurately), or perhaps salience due to the fact that some risks actually did materialize, could also account for these differences.

\footnotetext{
${ }^{9}$ We explored different specifications of our models in order to test conclusions for robustness. Results of these tests can be obtained from the authors.
} 
Table 3 reports HLM regressions of differences between real-time and retrospective risk assessments that test the timing and salience explanations controlling for other possible effects. First, Model 1 documents a significant positive difference of almost half a point on a 0-10 scale (0.48). Model 2 indicates an effect of the different questionnaires used in the two experimental conditions (at level 2). ${ }^{10}$ Model 3 suggests that whereas real-time emotional state (mean or deviations by occasion) explains no variance, the SAM variable valence does. Finally, at level 1 Model 4 shows no effect for salience ("Happened"), but there are effects for timing (smaller differences associated with later assessments), and the SAM variable arousal. In short, emotion experienced when risks are assessed - and especially arousal - contributes to differences between real-time and retrospective risk assessments.

Insert Table 3 about here

\section{Consistency in estimation}

In specifying the HLMs, we model risk perception as being impacted by emotional variables. However, if perceived risk also affects emotions, the assumptions of HLM could be violated and this could possibly lead to inconsistent parameter estimates. In our study, we manipulated neither risk perceptions nor emotions. Thus, we clearly cannot make statements about the directionality of effects. However, we can conduct tests that probe our assumptions and we provide the details of one such analysis in the Appendix.

In brief, we use the technique of instrumental variables to estimate the risk equation and employ Hausman's test of endogeneity to check whether the emotional variables are exogenous

\footnotetext{
${ }^{10}$ We have no explanation for this effect with the retrospective data. From our perspective, the important finding was that there was no effect for questionnaire type in the real-time judgments of risk (not shown in Tables 1 and 2).
} 
(Hausman, 1978). We find we cannot reject the null hypothesis that the emotional variables are exogenous in the risk equation.

In summary, the statistical tests conducted in the Appendix support the assumption that the parameter estimates presented in the main body of the paper are consistent, and hence, the conclusions we draw on the basis of the HLM regressions are valid.

\section{GENERAL DISCUSSION}

Our most striking finding is that simple measures of mood state and three emotional reactions (valence, arousal, and dominance) explain variations in perceptions of risk. Moreover, valence and arousal explain variance over and above that accounted for by the "rational" variables of assessed severity and possibility of losses. These results corroborate findings concerning the dual roles of reason and emotion in risk perception (Slovic et al., 2004; Slovic \& Peters, 2006) but and this is important - are an extension to randomly sampled events experienced in everyday life.

Interestingly, most situations faced by our respondents did not involve major decisions. For example, there were few, if any, mentions of catastrophic events such as terrorist attacks in which emotion might be expected to play an even greater role. Instead, our results show that emotion is pervasive in risk perception, even at the level of everyday trivia, and are thus consistent with the notion that the experiential cognitive system (Epstein, 1994) is constantly adjusting to what is perceived in the environment.

The study replicated a finding from a previous study that deviations in mood state are associated with risk perceptions - less risk with happier mood states (Hogarth et al., 2007) - and 
is consistent with results in the experimental literature (see, e.g., Isen, 1993). At the same time, a novel feature of our work was the exploration of the impact on risk perception of emotional states as measured by the three SAMs that capture emotional dimensions of valence, arousal, and dominance. We found that less risk was associated with happier valence, less arousal, and greater dominance. The directions of each of these relations are consistent with the fact that we were only considering negative impacts of risk (i.e., negative events). An interesting task for future research would be to investigate the effects of these emotions when risks are positive (e.g., facing the possibility of gaining money as when contemplating investments). For example, whereas valence might have a different sign with risks of positive payoffs, it is not clear that this would be the case for arousal.

Of the different emotional variables (SAMs), dominance had less impact in our data than valence and arousal. This was perhaps surprising because, a priori, one might imagine that feelings of control would be especially salient in the presence of risk. On the other hand, it is possible that the manikins for valence and arousal were easier for participants to interpret - see Figure 1.

The methods used in this research can be employed to refine further our understanding of the emotion-risk relation. For example, experimental findings differ as to whether emotional states have general as opposed to specific effects on risk attitudes. Some investigators have found general effects (Johnson \& Tversky, 1983) whereas other results support specificity (i.e., specific emotions affect correspondingly specific risk perceptions, DeSteno et al., 2000). Emotional reactions, however, may be multi-faceted (Barrett, 2006). Future studies with experience sampling using more targeted measures could illuminate this controversy in naturally occurring settings. 
Real-time assessments of risks were found to be greater than those made retrospectively. Our analysis demonstrated possible memory effects (more recent real-time assessments more consistent with retrospective judgments). However, it also showed that emotion experienced when risks were assessed (especially arousal) contributed to the observed differences. Given the prevalence of retrospective and prospective surveys of risk attitudes, these results have important implications (see also Stone et al., 1999).

The assumption of consistent estimation implicit in the regression analyses used in our work implies that mood and emotions impact risk perception as opposed to the reverse. Clearly, however, perceived risk can precede the experience of emotion. (Imagine, for example, how one might feel after hearing, for the first time, about the severe risks of an impending surgical intervention.) Nonetheless - and for the population of incidents we sampled - the hypothesis of consistent estimation was not rejected by our statistical tests (see Appendix). At the same time, we believe this issue needs further clarification and the use of a different experimental design to illuminate the most probable directions of effects and possible mediating variables. It is possible, for example, that whereas in some cases emotions impact perceived risk, in others it is perceived risk that impacts emotion. Much depends therefore, on what kinds of situations are sampled, something that our study explicitly did not control. On the other hand, we note that in our experimental design we did vary the order in which the questions about the emotional variables (SAMs) and perceived risk were elicited and found no effects.

It is important to emphasize that our methodology is based on the random sampling of situations. This allows making meaningful statements about the populations of experiences of our individual participants. As such, our investigation represents an illustration of the principles of representative design (Brunswik, 1944; 1956) and addresses a critical drawback of many 
studies of risk perception, namely, the inability to relate findings to the population of situations in which they are relevant. Our study is not, however, without methodological shortcomings. First, although the situations faced by our participants were sampled by a random process, the participants themselves were a convenience sample and thus we cannot assume that they are representative of the population at large. Clearly, the ideal study would sample both participants and situations at random. Second, by asking our participants to record their emotional reactions we might have unwittingly influenced their reports. Emotions have been shown to have unconscious effects (Ruys \& Stapel, 2008) and our study could have overlooked or misinterpreted these.

A further issue is that our study only investigates risk perception and not actual decisions. To what extent do mood and emotions affect decisions in the work place? This is an important topic for future research since, based on experimental evidence, moods can affect decisions (Isen, 1993; Slovic et al., 2002; Andrade \& Ariely, 2009). Moreover, in an ingenious field study of university admissions staff, Simonsohn (2007) found that decisions reflected mood changes that could be attributed to fluctuations in weather patterns. Changes in cloud cover had significant and systematic impacts on important decisions. Once again, however, we need to establish the generality of these kinds of findings.

Our research demonstrates the power of simple technology to collect meaningful samples of naturally occurring behavior. Contrary to modern ESM studies we did not use hand-held computers or other "high-tech" devices. Instead, we relied on the participants' own cellular telephones and small paper-and-pencil response pads. ${ }^{11}$ Our impression was that participants would have found responding on special hand-held computers to be more intrusive than our

\footnotetext{
${ }^{11} \mathrm{We}$ did however use a special computer program to dispatch messages indicating when responses were required.
} 
procedure. Indeed, since all of our participants always carried a cellular telephone on their person anyway, the addition of a small pad was a minimal distraction.

Finally, it is interesting to speculate how future technology might enrich these kinds of studies. For example, it is not hard to imagine devices that will be able to capture biological measurements of emotion that can corroborate the paper-and-pencil responses provided by our participants. As such, we can expect even greater scientific returns from studies based on the principles of representative design (Dhami et al., 2004). 


\section{REFERENCES}

Andrade, E. B., \& Ariely, D. (2009). The enduring effect of transient emotions on decision making. Organizational Behavior and Human Decision Processes, 109 (1), 1-8.

Balestra, P., \& Varadharajan-Krishnakumar, J. (1987). Full Information Estimations of a System of Simultaneous Equations with Error Component Structure. Econometric Theory, 3(2), 223-246.

Barrett, L. F. (2006). Are emotions natural kinds? Perspectives on Psychological Science, 1 (1), 28-58.

Bradley, M. M., \& Lang, P. J. (1994). Measuring emotion: The self-assessment manikin and the semantic differential. Journal of Behavioral Therapy and Experiential Psychiatry, 25, 4959.

Brunswik, E. (1944) Distal focusing of perception: Size constancy in a representative sample of situations, Psychological Monographs, 56(254), 1-49.

Brunswik, E. (1956). Perception and the representative design of experiments ( $2 d$ ed.). Berkeley, CA: University of California Press.

Byrk, A. S., \& Raudenbush, S. W. (2002). Hierarchical linear models: Applications and data analysis methods. (2nd ed.). Newbury Park: Sage Publications.

Byrnes, J. P., Miller, D. C., \& Schafer, W.D. (1999). Gender differences in risk taking: A metaanalysis. Psychological Bulletin, 125(3), 367-383.

Chaiken, S., \& Trope, Y. (1999). (Eds.) Dual-process theories in social psychology. New York, NY: Guilford. 
Denissen, J.J., Butalid, L., Penke, L. \& van Aken, M.A. (2008). The effects of weather on daily mood: a multilevel approach. Emotion, 8(5), 662-667.

DeSteno, D., Petty, R. E., Wegner, D. T., \& Rucker, D. D. (2000). Beyond valence in the perception of likelihood: The role of emotion specificity. Journal of Personality and Social Psychology, 78 (3), 397-416.

Dhami, M. K., Hertwig, R., \& Hoffrage, U. (2004). The role of representative design in an ecological approach to cognition. Psychological Bulletin, 130 (6), 959-988.

Epstein, S. (1994). Integration of the cognitive and psychological unconscious. American Psychologist, 49, 709-724.

Goldstein, H. (1995). Multilevel statistical models. (2nd ed.). Kendall's Library of Statistics 3. London, UK: Edward Arnold.

Hausman, J.A. (1978). Specification tests in econometrics, Econometrica, 46 (6), 1251-1271.

Hektner, J. M., Schmidt, J. A., \& Csikszentmihayli, M. (2007). Experience sampling method: Measuring the quality of everyday life. Thousand Oaks, CA: Sage Publications.

Hirshleifer, D. \& Shumway, T. (2003). Good Day Sunshine: Stock Returns and the Weather. Journal of Finance, 58(3),1009-1032.

Hogarth, R. M. (2005). The challenge of representative design in psychology and economics. Journal of Economic Methodology, 12 (2), 253-263.

Hogarth, R. M., Portell, M., \& Cuxart, A. (2007). What risks do people perceive in everyday life? A perspective gained from the experience sampling method (ESM). Risk Analysis, 27(6), 1427-1439.

Howarth, E. \& Hoffman, M. S., (1984). A multidimensional approach to the relationship between mood and weather. British Journal of Psychology, 75(1), 15-23. 
Hsee, C . K., \& Kunreuther, H. C. (2000). The affection effect in insurance decisions. Journal of Risk and Uncertainty, 20 (2), 141-159.

Hurlburt, R. T. (1997). Randomly sampling thinking in the natural environment. Journal of Consulting and Clinical Psychology, 67 (6), 941-949.

Isen, A. M. (1993). Positive affect and decision making. In M. Lewis \& J. M. Haviland (Eds.), Handbook of emotions (pp. 261-277). New York, NY: Guilford Press.

Johnson, E. J., \& Tversky, A. (1983). Affect, generalization, and the perception of risk. Journal of Personality and Social Psychology, 45 (1), 20-31.

Kahneman, D., \& Frederick, S. (2002). Representativeness revisited: Attribute substitution in intuitive judgment. In T. Gilovich, D. Griffin, \& D. Kahneman (Eds.), Heuristics and biases: The psychology of intuitive judgment (pp.49-81), New York, NY: Cambridge University Press.

Keller, M. C., Fredrickson, B. L., Ybarra, O., Côté, S., Johnson, K., Mikels, J., Conway, A. \& Wager, T. (2005). A Warm Heart and a Clear Head The Contingent Effects of Weather on Mood and Cognition, Psychological Science,16(9), 724-731.

Lerner, J. S., Gonzalez, R. M., Small, D. A., \& Fischhoff, B. (2003). Effects of fear and anger on perceived risks of terrorism: A national field experiment. Psychological Science, 14 (2), 144-150.

Loewenstein, G.F., Weber, E. U., Hsee, C. K., Welch, N. (2001). Risk as feelings. Psychological Bulletin, 127(2), 267-286.

Longford, N.T. (1993). Random coefficient models. Oxford: Oxford University Press. 
Rottenstreich, Y., \& Hsee, C. K. (2001). Money, kisses, and electric shocks: On the affective psychology of probability weighting. Psychological Science, 12, 185-190.

Ruys, K. I., \& Stapel, D. A. (2008). The secret life of emotions. Psychological Science, 19(4), 385391.

Sanders, J.L., \& Brizzolara, M.S. (1982). Relationships between weather and mood. Journal of General Psychology, 107, 155-156.

Saunders, E. M., Jr. (1993). Stock Prices and Wall Street Weather. American Economic Review, 83(5), 1337-1345

Simonsohn, U. (2007). Clouds make nerds look good: Field evidence of the impact of incidental factors on decision making. Journal of Behavioral Decision Making, 20 (2), 143-152.

Slovic, P. (2000). The perception of risk. London, UK: Earthscan Publications Ltd.

Slovic, P., Finucane, M. L., Peters, E., \& MacGregor, D. G. (2004). Risk as analysis and risk as feelings: Some thoughts about affect, reason, risk, and rationality. Risk Analysis, 24 (2), 311322.

Slovic, P., \& Peters, E. (2006). Risk perception and affect. Current Directions in Psychological Science, 15(6), 322-325.

Slovic, P., Finucane, M., Peters, E., \& MacGregor, D. (2002). The affect heuristic. In T. Gilovich, D. Griffin, \& D. Kahneman (Eds.). Intuitive judgment: Heuristics and biases (pp. 397-420). New York, NY: Cambridge University Press.

Snijders, T., \& R. Bosker (1999). Multilevel Analysis. An introduction to basic and advanced multilevel modeling. London: SAGE Publications. 
Stone, A. A., Shiffman, S. S., \& DeVries, M. W. (1999). Ecological momentary assessment. In D. Kahneman, E. Diener, \& N. Schwartz (Eds.). Well-being: The foundations of hedonic psychology (pp. 26-39). New York, NY: Russell Sage.

Sunstein, C. R. (2003). Terrorism and probability neglect. Journal of Risk and Uncertainty, 26 (2/3), 121-136.

Wooldridge, J. M. (2002). Econometric analysis of cross section and panel data. Cambridge, MA: MIT press. 


\section{Author Note}

Robin M. Hogarth, ICREA \& Universitat Pompeu Fabra; Mariona Portell, Universitat Autònoma de Barcelona; Anna Cuxart, Universitat Pompeu Fabra; Gueorgui I. Kolev, Universitat Pompeu Fabra. Address correspondence to Robin M. Hogarth, Universitat Pompeu Fabra, Ramon Trias Fargas 25-27, 08005 Barcelona, Spain, e-mail: robin.hogarth@upf.edu

We thank Joshua Klayman and Ellen Peters for their insightful comments. The research was

supported by the Spanish Ministerio de Educación y Ciencia, SEJ2006-27587-E/SOCI (to Hogarth). 
Table 1: Regression of perceived risk on mood state and SAM variables

\begin{tabular}{|c|c|c|c|c|c|c|c|c|c|}
\hline & & Model 1 & & Model 2 & & $\underline{\text { Model } 3}$ & & $\underline{\text { Model } 4}$ & \\
\hline \multicolumn{2}{|l|}{ Fixed effects } & \multicolumn{8}{|c|}{ Level 2 variables } \\
\hline \multicolumn{2}{|c|}{ Intercept } & 2.56 & 15.47 & 4.57 & 3.57 & 4.52 & 3.47 & 4.88 & 3.74 \\
\hline \multicolumn{2}{|c|}{ Mean mood state } & & & -0.36 & -1.89 & -0.20 & -1.02 & -0.23 & -1.18 \\
\hline \multicolumn{4}{|c|}{ Gender $(1=$ male $; 0=$ female $)$} & 1.18 & 3.59 & 1.11 & 3.38 & 1.14 & 3.45 \\
\hline \multicolumn{10}{|l|}{ Level 1 variables } \\
\hline \multicolumn{2}{|c|}{ Mood state (deviation) } & & & -0.28 & -10.91 & & & -0.12 & 4.11 \\
\hline \multirow[t]{3}{*}{ SAMs: } & Valence & & & & & 0.27 & 12.70 & 0.22 & 8.82 \\
\hline & Arousal & & & & & -0.25 & -12.66 & -0.26 & -13.03 \\
\hline & Dominance & & & & & -0.12 & -5.10 & -0.10 & -4.44 \\
\hline \multicolumn{10}{|l|}{ Random effects } \\
\hline \multicolumn{2}{|c|}{ Level 2 (individuals) variance } & \multicolumn{2}{|l|}{2.43} & \multicolumn{2}{|l|}{2.06} & \multicolumn{2}{|l|}{2.10} & \multicolumn{2}{|l|}{2.10} \\
\hline Level 1 (occasion & riance & \multicolumn{2}{|l|}{4.38} & \multicolumn{2}{|l|}{4.19} & \multicolumn{2}{|l|}{3.80} & \multicolumn{2}{|l|}{3.77} \\
\hline \multicolumn{10}{|l|}{ Model comparisons } \\
\hline \multicolumn{10}{|c|}{ Proportional reduction in prediction error relative to Model 1} \\
\hline Level 2 & ined proportion o & variance & & $14.6 \%$ & & \multicolumn{2}{|l|}{$13.6 \%$} & \multicolumn{2}{|l|}{$13.6 \%$} \\
\hline \multicolumn{4}{|c|}{ Level 1 explained proportion of variance } & $8.2 \%$ & & \multicolumn{2}{|l|}{$13.3 \%$} & \multicolumn{2}{|l|}{$13.7 \%$} \\
\hline \multicolumn{4}{|l|}{ Deviance } & $12,089.4$ & & $11,972.3$ & & $11,793.9$ & \\
\hline \multicolumn{2}{|c|}{ df (number of estimated parameters) } & \multicolumn{2}{|l|}{3} & \multicolumn{2}{|l|}{6} & \multicolumn{2}{|l|}{8} & \multicolumn{2}{|l|}{9} \\
\hline \multicolumn{4}{|c|}{$\mathrm{p}$-value for ratio test (relative to Model 1 ) } & \multicolumn{2}{|c|}{$\begin{aligned} & 298.03 \mathrm{df} \\
< & 0.001\end{aligned}$} & \multicolumn{2}{|c|}{$\begin{aligned} & 415.15 \mathrm{df} \\
< & 0.001\end{aligned}$} & $\begin{array}{r}593.5 \\
<0.001\end{array}$ & \\
\hline $\mathrm{p}$-value for ratio te & elative to previous & model, if nes & ed) & $\begin{array}{r}298.0 \\
<0.001\end{array}$ & & & & $\begin{array}{r}178.4 \\
<0.001\end{array}$ & \\
\hline
\end{tabular}

Note: Coefficients/variance components significant at $p<.001$ are in bold, significant at $p<.05$ are underlined, using t-tests or $\chi^{2}$ as appropriate. 
Table 2: Regression of perceived risk on both rational and emotional variables

Model $1 \quad$ Model $2 \quad \underline{\text { Model } 3} \quad \underline{\text { Model } 4}$

Fixed effects:

$\underline{\text { Coefficient t-ratio }} \underline{\text { Coefficient }} \underline{\mathrm{t} \text {-ratio }} \underline{\text { Coefficient }} \underline{\mathrm{t} \text {-ratio }} \underline{\text { Coefficient }} \underline{\mathrm{t} \text {-ratio }} \underline{\text { Coefficient } \underline{\mathrm{t} \text {-ratio }}}$

Level 2 variables

Intercept

Gender $(1=$ male; $0=$ female $)$

Mean mood state

Level 1 variables

Severity

Possibility

Severity*Possibility

Mood state (deviation)

SAMs:

$$
\text { Valence }
$$

Dominance

Random effects:

Level 2 (individuals) variance

Level 1 (occasions) variance

\subsection{6}

4.89

2.8813 .70

$-0.72-3.08$

$0.21 \quad 0.80$

$\begin{array}{ll}1.73 & 1.28\end{array}$

$\underline{0.83} \quad 2.39$

$\begin{array}{rr}-0.28 & -1.43\end{array}$

\begin{tabular}{ll}
1.65 & 1.71 \\
\hline
\end{tabular}

$\underline{0.82} \quad 2.31$

$\mathbf{0 . 4 4} 22.99$

$0.22 \quad 11.05$

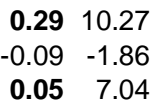

$\mathbf{0 . 3 0} 10.56$

$-0.08-1.67$

$\mathbf{0 . 0 4} 6.43$

$\mathbf{0 . 3 0} \quad 10.69$

$0.05 \quad 7.04$

$-0.15-5.45$

$\mathbf{0 . 0 4} 5.68$

$(-0.07)(-1.99)$

$\mathbf{0 . 1 5} \quad 5.37$

$-0.12 \quad-5.31$

$-0.04-1.55$

1.90

1.99
3.58

1.80
3.53

3.42

Model comparisons

Proportional reduction in prediction error relative to Model 1

Level 2 explained proportion of variance

$$
\begin{aligned}
& 2.03 \\
& 3.68
\end{aligned}
$$

3.58

3.53

$25.3 \%$

$26.2 \%$

$32.1 \%$

$29.4 \%$

$28.7 \%$

$23.4 \%$

$8,065.5$

$7,935.4$

9

$\mathrm{df}$ (number of estimated parameters)

$8,114.5$

6

$547.72 \mathrm{df}$

$<0.001$

$596.73 \mathrm{df}$

$<0.001$

$726.86 \mathrm{df}$

$<0.001$

$130.13 \mathrm{df}$

$49.01 \mathrm{df}$

$<0.001$
$29.5 \%$

$7,862.6$

12

$799.69 \mathrm{df}$

$<0.001$

$72.83 \mathrm{df}$

$<0.001$

Notes: (1) Coefficients/variance components significant at $p<.01$ are in bold, significant at $p<.05$ are underlined using

t-tests or $\chi^{2}$ as appropriate. Coefficients in parentheses did not prove to be significant when subject to tests of robustness.

(2) Degrees of freedom for level 2 variables and random coefficients are at least 61 . For all other variables they are at least 1875. 
Table 3: Regression of differences between real-time and retrospective judgments of risk on different possible explanatory variables

Model $1 \quad \underline{\text { Model } 2} \quad \underline{\text { Model } 3} \quad \underline{\text { Model } 4}$

Fixed effects:

$\underline{\text { Coefficient t-ratio }} \underline{\text { Coefficient }} \underline{\text { t-ratio }} \underline{\text { Coefficient }} \underline{\text { t-ratio }} \underline{\text { Coefficient }} \underline{\text { t-ratio }}$

Level 2 variables

Questionnaire (1=short; $0=$ long)

0.48

4.50

$\begin{array}{cc}\mathbf{0 . 6 7} & 5.39 \\ -\mathbf{0 . 6 1} & -2.75\end{array}$

\begin{tabular}{cc}
0.54 & 0.55 \\
-0.57 & -2.31 \\
\hline 0.10 & 0.40 \\
0.06 & 0.45
\end{tabular}

$0.85 \quad 0.84$

Gender ( $1=$ male; 0 = female)

Mean emotional state (30 occasions)

$\underline{-0.58}-2.28$

$0.11 \quad 0.44$

Level 1 variables

Emotional state (deviation)

Valence

Arousal

Dominance

Happened? (1=yes; $0=$ no)

When? ( $1=$ first week; $0=$ second week)

$\begin{array}{llll}0.03 & 0.43 & 0.00 & -0.02 \\ \underline{0.12} & 2.35 & 0.10 & 1.82 \\ -0.07 & -1.68 & \underline{-0.09} & -2.12 \\ -0.07 & -1.37 & -0.08 & -1.56 \\ & & -0.41 & -1.59 \\ & & \underline{0.38} & 2.36\end{array}$

Random effects:

\begin{tabular}{|c|c|c|c|c|}
\hline Level 2 (individuals) variance & 0.46 & 0.40 & 0.37 & 0.41 \\
\hline Level 1 (occasions) variance & 3.61 & 3.60 & 3.53 & 3.44 \\
\hline Deviance & $2,360.6$ & $2,356.3$ & $2,332.0$ & 2,231 \\
\hline df & 3 & 4 & 10 & \\
\hline$p$-value for ratio test & & $<0.05$ & $<0.001$ & $<0.0$ \\
\hline
\end{tabular}

Notes: (1) Coefficients/variance components significant at $p<.001$ are in bold, significant at $p<.05$ are underlined, using t-tests or $\chi^{2}$ as appropriate.

(2) Degrees of freedom for level 2 variables and random coefficients are at least 87 . For all other variables they are at least 519. 

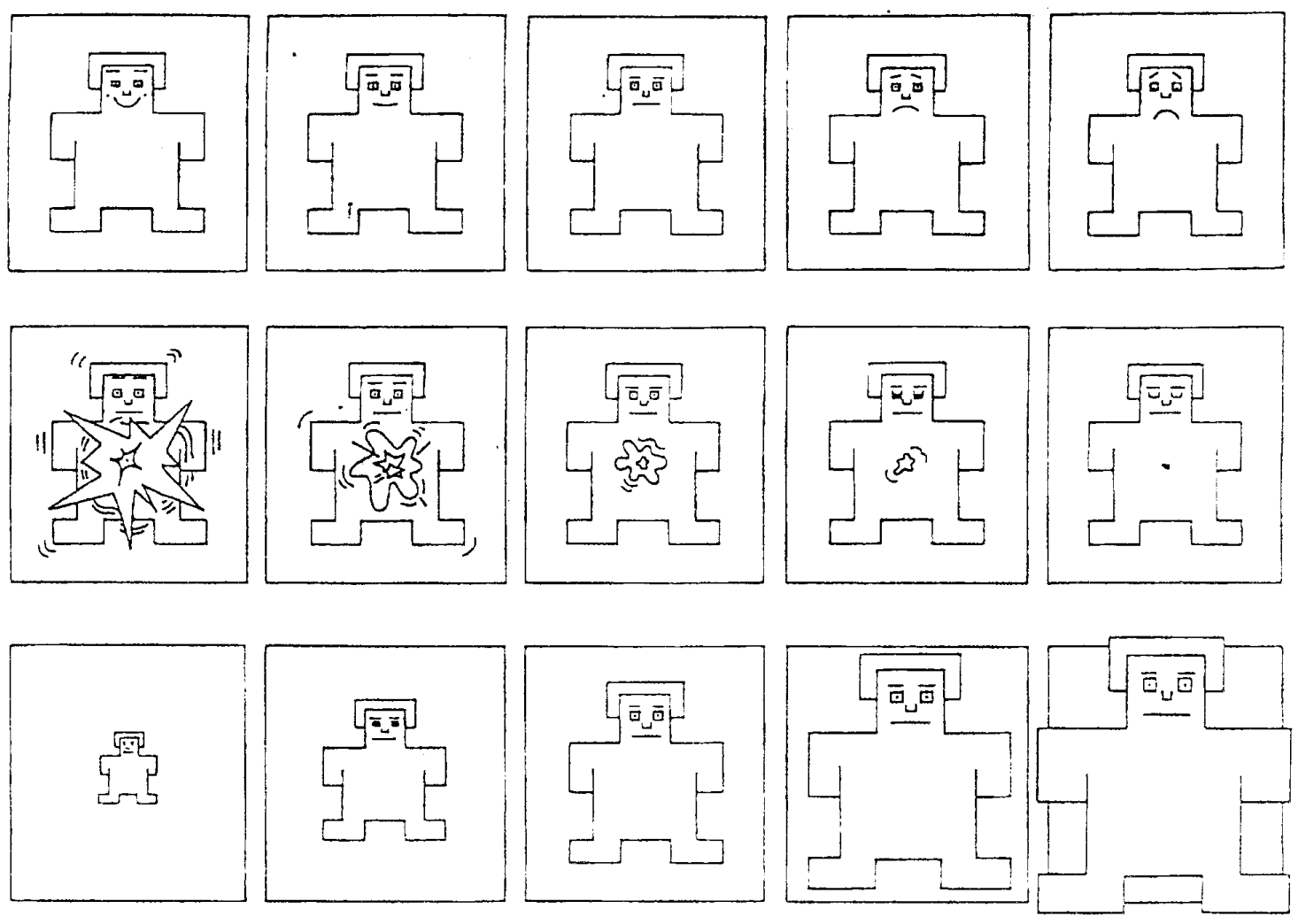

Figure 1: The Self-Assessment Manikins (SAMs) used to rate the affective dimensions of (a) valence (top panel), (b) arousal (middle panel), and (c) dominance (bottom panel) - Bradley and Lang (1994). 


\section{Appendix}

In the main body of the paper we assume that mood and emotions are exogenous regressors and we estimate their impact on risk assessments. However, in principle it is conceivable that risk assessment could also impact mood and emotions. For example, if learning the high risks of a medical operation leads to a worse mood, then mood would be an endogenous regressor, and we would incorrectly attribute the negative correlation between mood and risk to the impact of mood on risk (better mood leading to lower risk assessment), when in reality the opposite holds true (i.e., higher risk leading to worse mood). We use IV (instrumental variable) estimation to estimate consistently the population parameters that reflect the impact of mood and emotions on risk assessments, even if the exogeneity assumption is violated.

We estimate via GLS (generalized least squares) the parameters in the hierarchical linear models presented in the paper that can be described by the following structural equation

$$
R_{i j}=X_{i j} \beta_{1}+Z_{j} \beta_{2}+c_{j}+\varepsilon_{i j}
$$

defined over individuals $j=1,2, \ldots, 94$ and occasions $i=1,2, \ldots, 30$.

- $\quad \mathrm{R}_{\mathrm{ij}}$ is the risk assessment of person $j$ at occasion $i$;

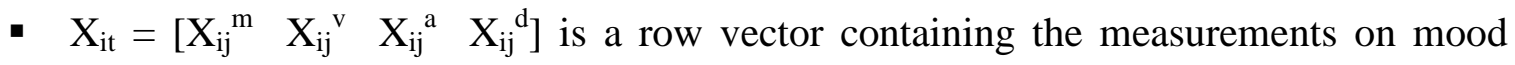
deviations, valence, arousal and dominance respectively, for person $j$ on occasion $i$;

- $\mathrm{Z}_{\mathrm{j}}$ is a row vector containing the mean mood state, female dummy variable, and a constant;

- $\beta_{1}, \beta_{2}$ are column vectors of population parameters of dimension conformable for multiplication; 
- $c_{\mathrm{j}}$ is an unobservable individual specific random effect;

- $\varepsilon_{\mathrm{ij}}$ is the idiosyncratic random shock to risk assessment for person $j$ at occasion $i$.

For GLS to estimate consistently the population parameters of interest, the regressors must be strictly exogenous. That is, the following condition must be satisfied in equation (A1):

$$
\mathrm{E}\left\{\left(\mathrm{c}_{\mathrm{j}}+\varepsilon_{\mathrm{ij}}\right) \mid\left[\mathrm{X}_{1 \mathrm{j}}, \mathrm{X}_{2 \mathrm{j}}, \ldots, \mathrm{X}_{30 \mathrm{j}}, \mathrm{Z}_{\mathrm{j}}\right]\right\}=0 .
$$

Regressors in a fully simultaneous system typically violate this condition, e.g., if risk assessments also impact mood deviations. When (A2) is violated, e.g., if the error term is correlated with mood deviations, we call the problematic regressor (mood deviation in this example) an endogenous regressor. IV estimation relies on finding for each potentially endogenous regressor one or more variables, ${ }^{12}$ called instruments, which are properly excluded from the structural equation of interest (i.e., instruments do not have structural impact on the dependent variable after all relevant exogenous and endogenous regressors have been controlled for in the structural equation of interest). Instruments have to satisfy the following two conditions: a) they are partially correlated with the endogenous regressor; b) they are uncorrelated with the error term.

We use weather variables and dummy variables denoting the time of the day when the responses were elicited as exogenous shifters of mood and emotional reactions. There is previous research showing effects of weather on mood (Howarth \& Hoffman, 1984; Sanders \& Brizzolara, 1982; Keller et al., 2005; Denissen et al., 2008) and research in finance showing that the weather where the stock exchange floor is located affects stock

\footnotetext{
${ }^{12}$ If in the equation of interest we have found exactly one instrument for each endogenous regressor, the equation is exactly identified. If we have more instruments than endogenous regressors, the equation is over-identified.
} 
returns, the implication being that the mood of traders at the stock exchange floor is a mediator between weather and returns (Saunders, 1993; Hirshleifer \& Shumway, 2003).

The weather variables that we use are temperature, tsunshine (daily total sunshine hours), and psunshine (sunshine hours as a percentage out of total expected). As the weather variables vary only across days (i.e., all the people and occasions within the same day are exposed to the same weather), we construct our instruments from the weather variables and additionally from their interactions with the regressors which we assume to be exogenous (uncorrelated with the error term), gender and the mean mood state, the latter being a proxy for personal disposition. This way we end up with instruments which employ the idea that weather and time of the day are exogenous shifters of mood and emotional reactions, but have both time series and cross sectional variation.

Therefore in the IV regressions we assume that the composite error in equation (A1) is exogenous with respect to the instruments constructed from weather variables, (temperature, tsunshine, psunshine, the interactions of these three with gender and the mean mood state), and the dummy variables denoting the time of the day during which messages were dispatched. We denote these instruments by the vector $\mathrm{W}_{\text {it }}$ where

$$
E\left[\left(c_{j}+\varepsilon_{i j}\right) \mid W_{1 j}, W_{2 j}, \ldots, W_{30 j}, Z_{j}\right]=0 .
$$

That is, the composite error in the risk equation is mean-independent of the weather and time of the day induced variation.

We use as an estimation technique the G2SLS estimator of Balestra and Varadharajan-Krishnakumar (1987), which is an Instrumental Variable version of the Generalized Least Squares personal random effects model we employ in the main body 
of the paper, and is an estimation technique appropriate under the orthogonality condition (A3).

We implement Hausman's (1978) test of endogeneity, comparing all the coefficients except the constant across the GLS and IV estimators.

The over-identifying restrictions test for the IV estimators involves the statistic $\mathrm{N}^{*} \mathrm{R}^{2}$ from the auxiliary regression of the IV composite residuals (i.e., the predicted values of $c_{i}+\varepsilon_{i t}$ ) on all the exogenous variables (including all the instruments), where $\mathrm{N}$ is the number of available observations. The statistic is distributed as $\chi^{2}$ with degrees of freedom equal to the number of over-identifying restrictions (Wooldridge, 2002, p.123).

As could be expected, the IV estimates are much less precise than the GLS estimates - see Table A1. The IV estimates of the mood deviation parameter remain significant and of much larger magnitude compared to the GLS estimates. The SAM variable of valence reverses sign in the IV regression, however it is insignificant. Dominance preserves its sign, but is insignificant as well. The estimated parameter for arousal increases slightly in magnitude in the IV regression compared to the GLS regression, and remains significant.

Insert Table A1 about here

Hausman (1978) tests do not reject the null hypothesis that the IV and GLS estimates differ only up to sampling error. Therefore we are not able to reject statistically the assumption we made in the main body of the paper (A2). In other words, the results in Table A1 suggest that 
i) the working assumption that mood deviations and the SAM variables are exogenous is reasonable and cannot be statistically rejected

ii) if anything, we might underestimate somewhat the impact of mood deviations on risk assessments in the main body of the paper ${ }^{13}$

iii) both the GLS and IV yield similar and significant estimates of the effect of arousal

iv) our instruments do not induce much variation in valence and dominance, and hence in the IV regressions we are not able to estimate precisely the separate effects of valence and dominance.

The over-identifying restrictions tests do not reject the validity of the instruments. We do not find statistical evidence suggesting that our instruments are a poor choice.

Since our study is not experimental, we clearly cannot confirm or disconfirm beyond any doubt the direction of effects of mood deviation and the SAMs to risk or vice-versa. However, the outcomes of the statistical tests presented in this appendix point to the fact that the parameter estimates that we report in the main body of the paper are consistent.

\footnotetext{
${ }^{13}$ The larger estimated effect of mood in the IV regression might be simply a result of sampling error. However if we focus only on the magnitude of the parameter estimate, it somewhat counterintuitively suggests that if risk assessment has an impact on mood, the effect would be surprising: namely, higher risk implying better mood.
} 
Table A1: Instrumental Variable regressions of perceived risk on mood state and SAM variables

$\begin{array}{lcccc} & (1)^{1} & (2)^{2} & (3)^{1} & (4)^{2} \\ & \text { GLS } & \text { IV } & \text { GLS } & \text { IV } \\ & & & & \\ \text { Mood state (deviation) } & \mathbf{- 0 . 2 8} & \mathbf{- 0 . 3 9} & \mathbf{- 0 . 1 2} & \underline{-0.67} \\ & (-10.9) & (-2.77) & (-4.11) & (-2.53) \\ \text { Valence } & & & \mathbf{0 . 2 2} & -0.41 \\ & & & (8.80) & (-1.17) \\ \text { Arousal } & & & \mathbf{- 0 . 2 6} & -0.31 \\ & & & (-13.0) & (-2.30) \\ \text { Dominance } & & & -\mathbf{0 . 1 0} & -0.076 \\ & & & (-4.43) & (-0.24) \\ \text { Mean mood state } & -0.36 & -0.36 & -0.23 & -0.50 \\ & (-1.85) & (-1.84) & (-1.15) & (-1.61) \\ \text { Gender(1=male;0=female) } & \mathbf{1 . 1 8} & \mathbf{1 . 1 8} & \mathbf{1 . 1 4} & \mathbf{1 . 2 2} \\ & (3.52) & (3.51) & (3.39) & (3.49) \\ \text { Constant } & \mathbf{4 . 5 7} & \mathbf{4 . 5 7} & \mathbf{4 . 8 8} & \mathbf{9 . 1 9} \\ & (3.49) & (3.48) & (3.67) & (3.27) \\ \text { Hausman test } & & & & 5.06 \\ \text { [p-value] } & & 0.70 & & {[0.54]} \\ \text { Over-identifying restrictions test }{ }^{4} & & {[0.87]} & & 5.23 \\ \text { [p-value] } & & 7.66 & & {[0.87]} \\ \text { Observations } & & {[0.86]} & & 2767\end{array}$

$t$ statistics in parentheses, p-values in square brackets

Coefficients significant at $\mathrm{p}<0.01$ are in bold, significant at $\mathrm{p}<0.05$ are underlined.

${ }^{1}$ First and third columns reproduce the GLS regression from the main body of the paper.

${ }^{2}$ Columns 2 and 4 are Instrumental Variable (IV) estimators. The G2SLS estimator due to Balestra and Varadharajan-Krishnakumar is used. The instruments employed are six dummy variables denoting the time of the day when the messages were dispatched, temperature, tsunshine (daily total sunshine hours), psunshine (sunshine hours as a percentage out of total expected) and the interactions of the latter three with Gender and Mean mood state. The variables instrumented and treated as potentially endogenous are Mood state (deviation), Valence, Arousal and Dominance. Variables treated as exogenous are Gender and Mean mood state.

${ }^{3}$ Hausman (1978) tests that the IV estimates are not statistically different from the GLS estimates. In columns 3 the test statistic is $\chi_{3}^{2}$ distributed, in columns 4 it is $\chi_{6}^{2}$ distributed (i.e., the comparison is based on all the estimated parameters in the model without the constant). In none of the cases does the test statistic reject the null hypothesis that the GLS and IV are equal, at conventional levels of significance.

${ }^{4}$ Over-identifying restrictions test. The test statistic is $\chi_{13}{ }^{2}$ distributed in column 2 and $\chi_{10}{ }^{2}$ distributed in column 4. In none of the cases does the test reject the null hypothesis that the over-identifying restrictions hold true. 